\title{
"Financial and economic aspects of bioenergy development in the context of providing energy independence of Ukraine"
}

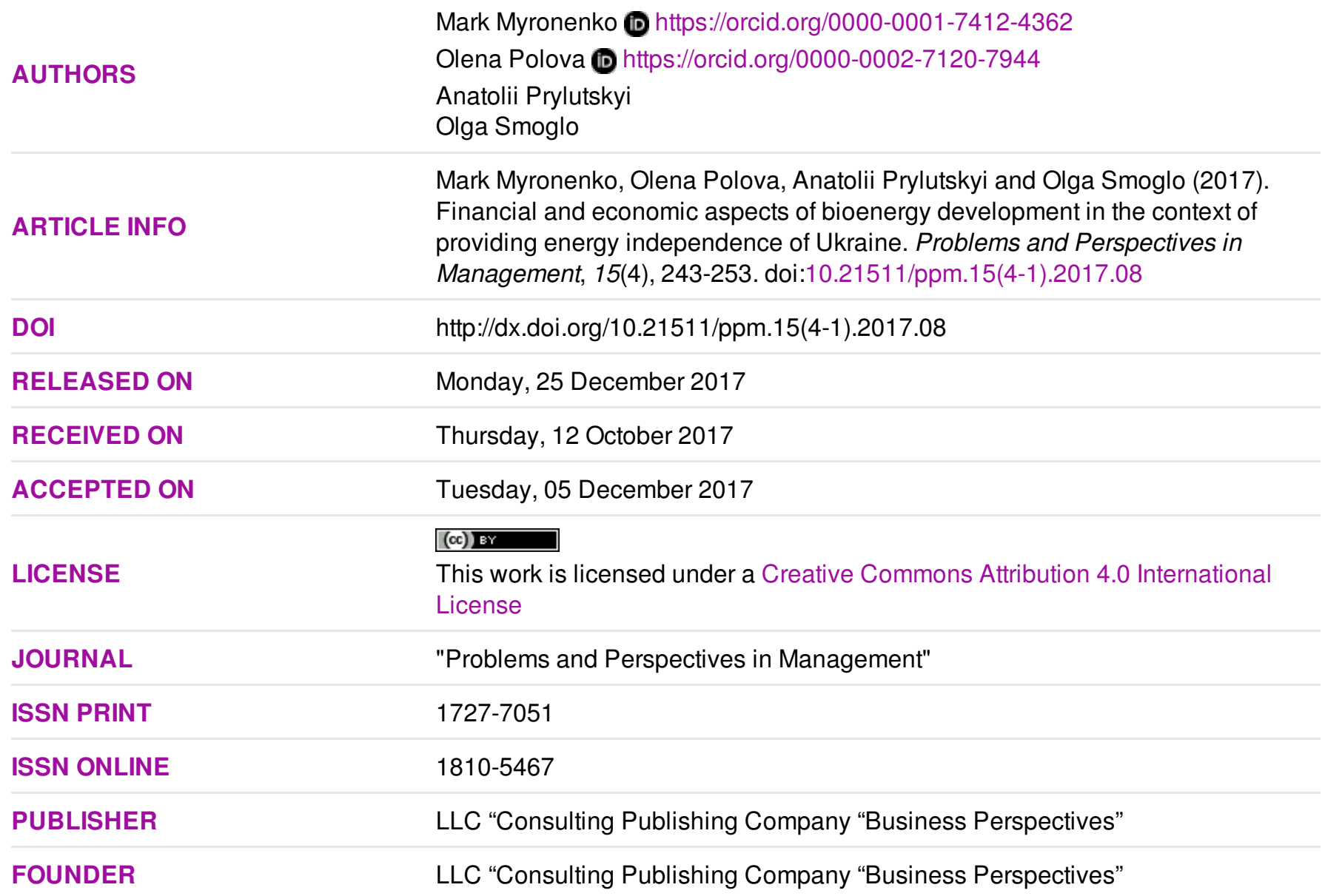

NUMBER OF REFERENCES

18
NUMBER OF FIGURES

1
NUMBER OF TABLES

1

(C) The author(s) 2023. This publication is an open access article. 


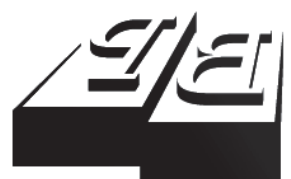

BUSINESS PERSPECTIVES

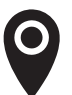

LLC "CPC "Business Perspectives" Hryhorii Skovoroda lane, 10, Sumy, 40022, Ukraine

www.businessperspectives.org

Received on: $12^{\text {th }}$ of October, 2017 Accepted on: $5^{\text {th }}$ of December, 2017

(C) Mark Myronenko, Olena Polova, Anatolii Prylutskyi, Olga Smoglo, 2017

Mark Myronenko, Doctor of Public Administration, Associate Professor of the Department of Finance, Vinnytsia Trade and Economic Institute KNTEU, Ukraine.

Olena Polova, Doctor of Economic Sciences, Associate Professor of the Department of Finance, Vinnytsia National Agrarian University, Ukraine.

Anatolii Prylutskyi, Ph.D. in Economics, Associate Professor of the Department of International Relations, Vinnytsia National Agrarian University, Ukraine.

Olga Smoglo, Ph.D. in Economics, Associate Professor of the Department of Finance, Vinnytsia Trade and Economic Institute KNTEU, Ukraine.

\section{(ㄷ)(i)}

This is an Open Access article, distributed under the terms of the Creative Commons Attribution 4.0 International license, which permits unrestricted re-use, distribution, and reproduction in any medium, provided the original work is properly cited.
Mark Myronenko (Ukraine), Olena Polova (Ukraine),

Anatolii Prylutskyi (Ukraine), Olga Smoglo (Ukraine)

\section{FINANCIAL AND ECONOMIC ASPECTS OF BIOENERGY DEVELOPMENT IN THE CONTEXT OF PROVIDING ENERGY INDEPENDENCE OF UKRAINE}

\begin{abstract}
The article deals with financial and economic meaning of bioenergy as an important component of the country's energy security. The problem of transition to renewable energy sources, in particular biofuels, was investigated. The relevance of research is that biofuels can fully replace traditional energy resources, increase the level of economic efficiency of production and competitiveness of national economy, as well as reduce amount of harmful emissions into the environment. The purpose of research is to study and develop theoretical and practical principles of financial and economic development of bioenergy and its role in ensuring energy independence of Ukraine.
\end{abstract}

In the context of financial and economic crisis and political instability, the development of bioenergy industry is of priority in dealing with main social and economic problems. One of the main aspects of bioenergy development is states' concern and use of targeted state funding. Moreover, other perspective ways to implement bioenergy technologies in Ukraine are public private partnership and attraction of foreign direct investments.

Economic assessment of different ways of full or partial replacement of natural gas has shown that they can be supplied with biomass, while the total capacity of introduced objects according to the bioenergy development program can save natural energy resources. According to the formula of the method of average medium, the forecast of optimistic and pessimistic scenario of energy potential development is developed.

Energy independence of Ukraine can be ensured through effective implementation of alternative energy with full state support, which will lead to acceleration of economic development of the territories, increasing level of life of people and environmental security of the country.

\section{Keywords bioenergy, development, finance, economics, energy resources, environmental safety, economic growth}

\section{JEL Classification L50, G18, Q43}

\section{INTRODUCTION}

Relevance of bioenergy development in Ukraine increases under the influence of a rather critical situation with the use of traditional energy sources, first of all imported gas. Moreover, world trends show a continuing increase of prices on traditional fuels in the future. The cost of imported natural gas in Ukraine already exceeds the average cost of this energy source in the countries of the European Union, while the efficiency of using this gas in Ukraine is much lower than in European countries. Considering that the share of natural gas reaches the mark of $40 \%$ in the general energy balance of Ukraine, and in the heat supply sector, it exceeds $65 \%$, it can be stated that the situation looks rather critical. 
It is necessary to focus not only on the basic data on the cost price of energy production and capital investments in the construction of the relevant facilities by comparing the economic efficiency of bioenergy and traditional energy, but also taking into account the future risks. The last ones are caused by rising prices for traditional fuels and environmental costs. Moreover, the health of the population has to be preserved in the conditions of growing pollution, which is emitted by the heat of electric stations, which operate only through the use of coal, fuel oil and gas. After considering the abovementioned risks, we can conclude that, bioenergy technologies in the coming decades will be able to compete with traditional energy technologies in the electricity generation market.

A number of sources and tools can be used to finance alternative energy projects, in particular bioenergy in Ukraine: state budget, city budget, loans and grants from international credit institutions, loans from Ukrainian banks, commercial loans, enterprises' own funds, international technical support projects, financial leasing, creation of public-private partnership, other instruments and sources of funds, which are not prohibited by Ukrainian legislation.

However, all the abovementioned sources of finance have certain limitations and usage specifics, which have to be taken into account while choosing them to finance certain projects for the development of bioenergy and other alternative energy sources.

Creation of public-private partnership according to the law of Ukraine "On public private partnership" is a useful tool for implementation of alternative energy projects. A state partner is a territorial community, which creates favorable conditions for the implementation of alternative energy projects, and a private partner ensures its financing and implementation. However, in order to prepare a public-private partnership project (draft agreement, selection of a private partner, etc.), local budgets should provide funds.

Moreover, it is necessary to actively promote projects on implementation of alternative energy, the realization of which is financed by voluntary contributions of citizens, legal entities, donations, sponsorship funds, etc. To do this, a competent information policy on the effective implementation of alternative energy projects has to be conducted.

\section{LITERATURE REVIEW}

Potential reserves of energy resources in the world is capable to provide continuously increasing energy requirements of mankind in the long term. However, assessment of their volume can conclude that renewable energy in its reserves is much higher than non-renewable. Intensive development of economic activity and use of non-renewable natural resources today are a great concern due to the risk of violation of ecological balance in the environment because of burning huge amount of organic fuel and emissions of various harmful substances. Environmental problem is a problem of environmental preservation of human society, flora and fauna. Besides, available energy resources should be used rationally and cost-effectively.

An important socio-economic value in agriculture has self-improving organic matter, which is gen- erated by plants in the process of photosynthesis as a biomass. The primary source of biomass is wood, crops, algae. Production and processing of biomass for energy has the following advantages: restoration, capacity for energy storage for use at any time, relatively not high cost, ecological safety. In the total amount of biomass, byproducts of plant and animal waste occupy a significant place. Therefore, the study of ecological and economic features of the conversion of various types of biomass to energy through the introduction of biotechnology is considered as an innovative process. These process represents a scientific interest, which determines the relevance of its further study.

The problem of macroeconomic management of energy aspects development with the use of alternative energy sources from the perspective of the innovation process to ensure energy and environmental security was investigated by leading scientists, in par- 
ticular Geletukha (2015), Kaletnik (2008), Matveyev (2008), Messel-Veselyak (2011), Solovey (2007) and others. However, despite the large number of scientific works on bioenergy in Ukraine, the issue requires further research towards finding alternative sources of energy as a tool for innovation process of environmental and socio-economic growth.

The work of Geletukha, Zhelezna, and Zhovmir (2010) is devoted to the methodology of energy potential estimation of agriculture plants and their primary and secondary wastes. The study states that important prerequisite for the successful use of biomass for energy needs is the proper assessment of its potential. There are three main types of biomass potential: theoretically feasible (theoretical), technically accessible (technical) and economically feasible (economic).

Edward Smeets (2008) in his work "Edward Smeets. General base line and principles" and Martijn Vis (2010) in his work "Harmonization of biomass resource assessments" investigated bioenergy and identified two main approaches to assessing the potential of biomass - resource-oriented (assessment of the use of biomass by various end users) and focused on energy needs (evaluated the competitiveness of various biomass energy technologies compared to other types of renewable energy sources and traditional fuels, as well as evaluated the financial-economic effect of using alternative energy sources).

The research by Makarchuk and Savchuk (2011) in the monograph "Bioenergy potential of agricultural production: economic dimension, forecast of use" is devoted to the theoretical and methodological principles of the formation and use of bioenergy potential of agricultural production, improvement of methodical tools for analyzing the efficiency of bioenergetics potential, which synthesizes the results of energy, cost and environmental assessment. Authors offered the concept of formation and use bioresources potential of agricultural enterprises, which determines the strategy of development of biofuel industry taking into account natural, political, economic, social and environmental factors of influence.

Khivrych (2011) in his paper "Energy Plants as Biofuel Raw Materials" made a significant contribution to the study of various aspects of the prob- lem of using the energy potential of biomass, described the energy and economic effects of plants for the production of biofuels. The study of the potential of biomass energy crops is of particular interest, among which the most common are: perennial herbaceous culture of the miskanthus and woody plants - willow, poplar, alder, and acacia. These energy crops can produce large biomass increments in a relatively short period of time. In terms of energy equivalent, the costs of growing such crops are much lower than the cost of energy derived from traditional sources.

Yermilov (2006) notes that only by subordinating its own energy policy to such goals as energy security, energy efficiency and macroeconomic balance achievement, Ukraine will be able to respond adequately to the challenges of the present and to counteract the effects of adverse fluctuations of the external and internal environment on national competitiveness.

Mykytenko (2006) emphasizes the fact that scientifically grounded strategy of balanced economic development becomes one of the main means of preventing possible threats to uninterrupted energy supply of all production spheres of the state.

Myronenko and Polova (2016) note that in terms of complex market relations, alternative energy is an effective instrument for the economic development of the regions. It plays an important role in expanded reproduced production, providing work places, affects the competitiveness of goods and services, and also serves a source of additional income. That is why the replacement of traditional sources of energy with alternative ones is a topical issue, the solution of which allows the state to guarantee a high level of energy independence.

Polova (2010) notes that active scientific and technical development in many countries of the world demands from Ukraine the adoption of effective financial, economic, organizational and technological decisions concerning the introduction of innovations for the purpose of obtaining a competitive product. Domestic technological and technical developments in the field of alternative energy sources allow obtaining the necessary amount of energy at low cost and widely use it in meeting production, social and consumer needs. 
Attention of researchers is mainly focused on the energy and ecological significance of bioenergy, as a factor in technological development. At the same time, thorough development of energy projects of socio-economic development of regions has to be done in the conditions of financial and economic instability, technological transformations, and investment-innovation modernization. In addition, the issues of financial security and economic efficiency of production and use of alternative energy sources and biotechnology in particular are still insufficiently studied.

\section{AIMS}

The purpose of the research is to study and develop theoretical and practical principles of financial and economic development of bioenergy and its role in ensuring energy independence of Ukraine.

\section{METHODS}

Theoretical and methodological basis of solving the problem of financial and economic development of bioenergy in the context of providing energy independence of the country is a dialectical method of knowledge of economic phenomena and processes, works of Ukrainian and foreign scientists on the issue of effective implementation of alternative energy and reasoning of financial and economic aspects of its development.

Methodological basis of this study consists of various methods: analysis and synthesis (summariz- • ing scientific approaches that determine the need for renewable energy production, defining financing sources for bioenergy development projects); monographic (extended study of factors that influence bioenergy development); economic analysis (evaluation of the production of renewable energy sources; monitoring the study of problems and defining the prospects for the implementation of bioenergy technologies for the full or partial replacement of natural gas; assessment of financial provision sources for bioenergy technologies introduction); economic-statistical method (when developing the forecast of the biomass energy potential in Ukraine), tabular and graphical methods of displaying information.
In order to evaluate the potential of biomass in Ukraine, we advise to use an in-depth statistical method to obtain results. The technical potential is calculated from the theoretical (potential) through the coefficient of technical availability. The economic potential is calculated from the technical (potential) using the energy utilization factor (Geletukha, Zhelezna, Zhovmir et. al., 2010).

The formula of the fluid medium method helped us to make a forecast of the optimistic, pessimistic scenario of the development of the energy potential:

$$
\bar{X}(k)=\frac{1}{n} \sum_{t-k}^{n+k} X(t),
$$

where $n$-smoothing period, $k$ - the number of a member of a row whose value is replaced by the average.

All methods are combined by a systematic approach to the definition of economic phenomena and processes.

\section{RESULTS}

Alternative energy sources and biotechnology play an important role in overcoming the crisis in the energy sector, which is due to the growth of energy consumption in society. Wide introduction of biotechnologics into the world economy can be also displayed in new terms that have occurred to indicate the global nature of this process:

"white biotechnology" - application of biotechnological methods in industrial production;

"red biotechnology" - in pharmaceutical industry and medicine;

"green biotechnology" - in agricultural production in the field of plant growing and stockbreeding;

"blue biotechnology" - biotechnology for artificial growth and further processing of aquatic organisms (aquaculture or mariculture).

Biomass is one of the priority species among other renewable energy sources in most countries due 


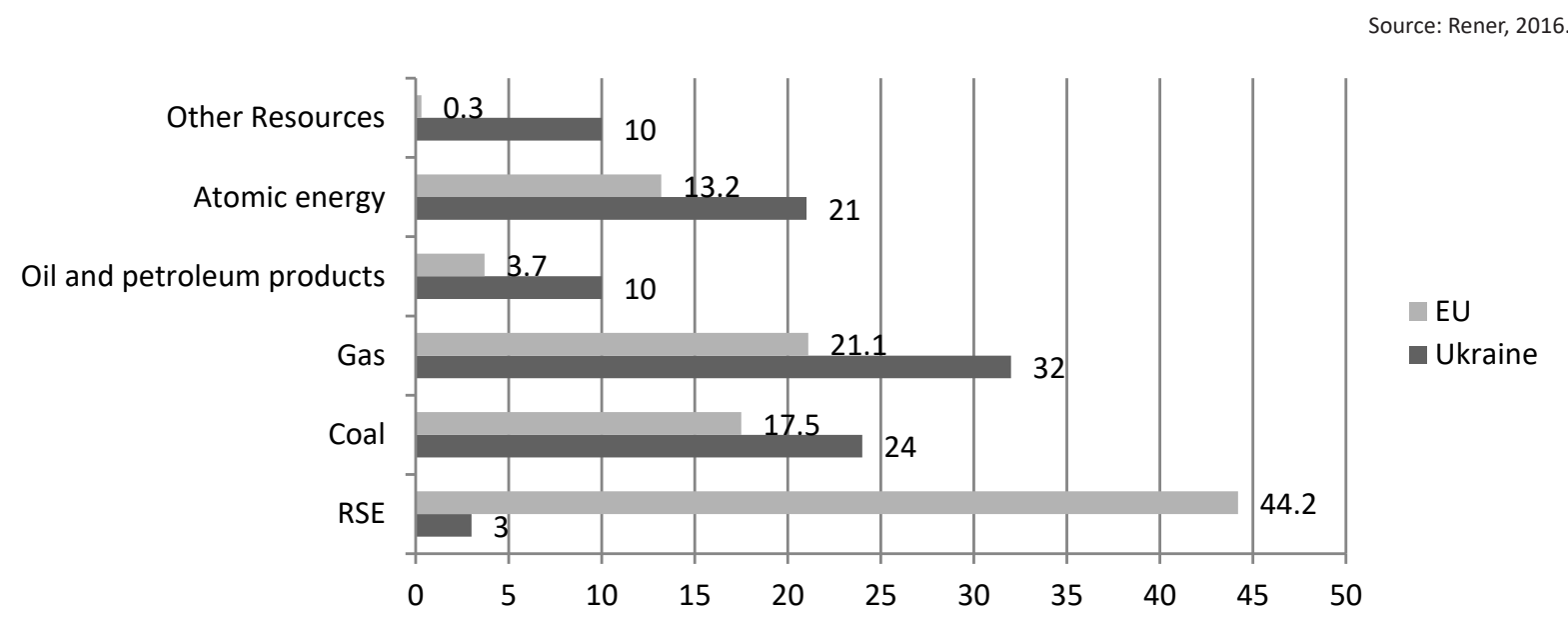

Figure 1. Structure of energy resources supplying in EU and Ukraine in 2015, \%

to the great potential, short payback periods, environmental benefits. At the end of the XX century, total world primary energy resources amounted to about 8.5 billion tons, of which about 7 billion tons accounted for organic fuel. The total energy potential of the entire vegetation of our planet is about 70 billion tons, that is, 10 times higher than usage of fossil fuels. Today biomass covers an average of $15 \%$ of the total primary energy resources consumption in the world, and in industrialized countries, it is on average: United States - 3.2\%; Denmark - 6\%; Austria - 12\%; Sweden - 18\%; Finland $-23 \%$. The share of wood used to generate energy is: in Denmark - $61 \%$ of the total wood exported from the forests, France - 56\%, Spain - 44\%, Switzerland - 56\%. On average, in Europe, the pace of its use grows by $7.3 \%$ annually. Moreover, experience shows that processing of biomass gives 4 times more energy than the nuclear power industry of the developed countries gives.

The use of bioenergy is economically feasible, because biofuel is much cheaper than natural gas. For example, 1 GJ, obtained with biofuel, costs about $95 \mathrm{UAH}$, but the same amount produced with natural gas is about $215 \mathrm{UAH}$.

For many countries, energy based on renewable energy sources is an important component of power supply of the state. It plays a significant role in power supplying to China, the USA, Canada, Brazil and other countries. The leaders in the production of alternative energy sources are the United States, China and India. In the world and European energetics, over the past 15-20 years re- newable energy sources (RES) in the world total energy output reaches more than $23 \%$, and in EU countries $-44.2 \%$ (Figure 1).

In Ukraine, renewable energy in total production makes $3 \%$. It is necessary to redirect the national energy system to renewable energy sources, if Ukraine is going to join global processes.

The advantages of renewable energy sources over traditional ones (gas, coal and uranium) is that they are unlimited in the amount of their stocks, and can be used without harming nature and humans. Implementation of RES will lead to a significant reduction of harmful emissions into the atmosphere and will significantly improve the ecological state of the planet, in terms of global warming in accordance with the implementation of the Kyoto Protocol to the United Nations Framework Convention on Climate Change in the field of energy efficiency and related environmental aspects.

World energy security is determined, first of all, by availability of fuel and other resources for energy production. The gross energy potential of biomass on Earth is $1014 \mathrm{~W}$, which is 10 times higher than power of nowaday energetics. So, biomass as an energy source plays a significant role in the global energy balance, its share accounts for $10.7 \%$ of the total energy consumption, or more than 1500 million tons of t.c.f. (t.c.f. - ton of conventional fuel, the specific heat of combustion which is $7000 \mathrm{kcal} / \mathrm{kg}$, or in the SI system $29.3 \mathrm{MJ} / \mathrm{kg}$ ). 
Biofuels have many advantages over traditional fuels:

- biofuel is obtained through the processing of plant products which does not worsen structural and chemical composition of the soils in crop rotation system and products of animal origin by waste recycling;

- the emission of carbon dioxide (CO2) is significantly less than that of ordinary fuel;

- compared to petrol and diesel fuel, it shows excellent results for the indicators of carbon monoxide combustion products, residual particles and soot;

- biofuels do not harm plants, animals or water sources if it's contact with biological objects. In addition, it undergoes a practically complete biological decay.

According to the OECD/FAO by 2020, biofuel production in the world could amount to 745.9 million tonnes and per capita - $66.1 \mathrm{~kg}$ per year (World Bank, 2017).

In the world countries, the following scale of implementation is outlined: the EU plans to achieve $10 \%$ share of biofuels in the total amount of fuel till 2020 used by transport; China plans to reach $15 \%$ of this share of biofuels till 2020; India plans to increase this share to $10 \%$ till 2020; Australia aspires to 5-6\% till 2020; US plans to increase biofuel production by more than 10 times till 2030 in comparison with volume of consumption in 2010. Developed countries, having assessed the high prospects for obtaining biofuels, included this area as one of the priority and provided support at the state level. As a result, today the US share in the global volume of biotech products is $42 \%$, the European Union $-22 \%$, China - 10\%, India - 2\% (Rener, 2016).

For Ukraine, the use of biofuels is an effective way to get rid of external energy dependence, which is in line with the tasks of the current Strategy of National Security of Ukraine and the Energy Strategy of Ukraine for the period till 2030, which outlines the strategic guidelines for the development of Ukraine's fuel and energy complex. The energy strategy of Ukraine is divided into three stages, and each of them has identified priority tasks:

the first stage - the reform of the energy sector (till 2020);

- the second stage - optimization and innovative development of the energy infrastructure (till 2025);

- the third - ensuring sustainable development (till 2035).

The result of the implementation of the Energy Strategy should be the transformation of the fuel and energy complex of Ukraine from the problematic, which requires constant state support, to modern competitive and efficient industry, and till 2035, the share of RES should be 25\% (Association of Bioenergy Structures, 2017).

One of the most important elements of bioenergy development is the state's interest and the introduction of direct state budget financing - starting with the production of quality raw materials and ending with the stimulation of a potential enduser. The motivating factor for the propagation of the use of solid biofuels can be considered as initiated efforts to replace the gas for heating.

In our view, the mechanisms for stimulating the development of renewable energy in Ukraine include a number of accepted government regulations regarding the replacement of natural gas with alternative fuels. The plan of short- and medium-term measures for reducing the volume of natural gas consumption includes:

- granting priority status for investment projects on the transfer of consumers from natural to other fuels and energy;

- implementation of the term "biomass" into national legislation in accordance with Directive 2009/28/EC;

- development of technical conditions for acceptance to Ukraine's gas transport system biome thane, mechanism of stimulating its production and consumption; 
- amendments to Ukraine's Energy Strategy until 2030 in the part of reducing the consumption of natural gas and increasing the volume of renewable energy sources and alternative fuels use, etc.

Company GFA Consulting Group prepared an overview of funding sources for bioenergy projects in Ukraine within project BIO-PROM. The analysis focused on international development programs, aimed at supporting the RES sector in Ukraine. Domestic private banks may also provide individual additional funding conditions for developers of new projects. More ower, some banks in EU countries support the export of equipment for the development of RES business.

Financing programs for investment projects in Ukraine:

- EU funds (USELF - Program of Financing Alternative Energy in Ukraine; UKEEP - Ukrainian Energy Efficiency increase Program;

- USEFF - Program of Financing of Alternative Energy, as a prolongation of UKEEP);

- Domestic funds (GGF - Green Development Fund for Southeast Europe;

- DEG - Climate partnership with the private sector;

- IFU/KIF - Investment Fund for Developing Countries/Danish Climate Investment Fund);

- international consortiums (NEFCO - lending to environmentally friendly production).

Austria is one of the largest donors of technical support for Ukraine in the energy saving segment. This Austrian Federal Ministry of finance is a donor of the Ukrainian Energy Efficiency Program (UKEEP). Such support is aimed at independent consulting of Ukrainian enterprises and partner banks on energy efficiency issues. The program was created for private enterprises of Ukraine, which intend to invest in projects of energy consumption reduction by replacing the main or auxiliary equipment and in projects using renewable energy sources. Currently, projects are funded through Ukrainian partner banks - Ukreximbank and Raiffeisen Bank Aval. Due to donors support, projects have been implemented in a wide range of Ukrainian industry sectors and agriculture. Using European experience on Ukrainian enterprises is an important way to reach energy independence in Ukraine.

Ukraine has great potential for reproductive energy sources development. Biomass and energy plants replace more than 3,3 billions $\mathrm{m}^{3}$ per year of natural gas, which makes it possible to exploit about $3670 \mathrm{MW}$ of biomass heat capacity. In order to develop the potential of using bioenergy technologies, the use of biomass and energy crops in municipal heat and hot water supply in the regions of Ukraine is carried out. Today there is a number of implemented regional projects for the generation of thermal energy from biomass (Danchuk, 2015), in particular.

USAID "Local Alternative Energy Sources" funds have developed project documentation for the reconstruction of a boiler house that will produce heat energy from straw (Myrgorod, Poltava region, 2015 ) in the amount of $\$ 1 \mathrm{mln}$. The reconstruction will reduce the consumption of natural gas by 0.6 million cubic meters per year. In the monetary equivalent, the annual savings of the local budget will amount to about UAH 2 million. The heat will be received by 10 multi-apartment buildings, schools and a kindergarten.

According to the United Nations Development Program (UNDP) and the Global Environment Facility (GEF) "Development and commercialization of bioenergy technologies in the municipal sector in Ukraine", financing of the first microproject on the transition of municipal supply to straw pellets was done (Uman, Cherkasy region, $2015)$ in the amount of 500 thousand euros. The transfer of boilers, which provide the heat supply of these educational institutions from natural gas to biofuels, will allow to reduce the expenses of the city budget for heating by 2.2 times, or by more than UAH 700 thousand per year; with the participation of the city council, Municipal Electricity Development Center and private investor LLC "Universal Development Group", with the assistance of the State Department of 
Energy Efficiency and Khmelnytsky Regional State Administration, transfer of communal boiler-houses for heating with straw and wood chips of Miskantus was financed (KamyanetsPodilsky, Khmelnytsky region, 2014). This project allowed replacing natural gas with an annual consumption of 30.3 million $\mathrm{m}^{3}$ and creating about 200 workplaces. Local budget savings amounted in about UAH 20 million per year and other projects.

The economic assessment of various options for the complete or partial replacement of natural gas has shown that they can be supplied with biomass, and the total capacity of the introduced objects for bioenergy development programs can save natural energy resources each year. In order to achieve this goal, Ukraine has a sufficient potential for biomass available for energy production - more than 32 million tons of fuel equivalent per year, according to 2016 research (Geletukha, Zhelezna, Zhovmir et al., 2010).

The assessment of the energy potential of biomass is performed on the basis of the calculation of three types of potential: theoretically feasible (theoretical), technically accessible (technical) and economically feasible (economic) (Smeets, 2008; Martijn, 2010).

Using the formula method of current average (Formula 1), we will develop a forecast of an optimistic, pessimistic scenario for the development of the energy potential of Ukraine (Table 1).

The main components of the energy potential are primary agricultural waste (straw, corn and corn waste for grains and sunflower), and energy crops, whose cultivation on an industrial scale has been actively developing in the country in recent years (Makarchuk, 2011; Khivrych, 2011).

The use of plant biomass provided its continuous restoration does not lead to an increase in the concentration of $\mathrm{CO} 2$ in the atmosphere. In general, the economic potential of agricultural waste amounts to 14.99 million tons of fuel equivalent per year (46.7\%), energy crops - 9.96 million tons of fuel equivalent per year (31\%).

The prognosis of the energy potential of biomass in Ukraine for 2020-2030 shows the strategic di-

Table 1. Energy potential of biomass prognosis in Ukraine for 2020-2030

\begin{tabular}{|c|c|c|c|c|c|c|c|c|}
\hline \multirow{3}{*}{ Biomass } & \multirow{2}{*}{$\begin{array}{l}\text { Theoretical } \\
\text { potential, mln } \\
\text { tn. f. e. }\end{array}$} & \multirow{3}{*}{$\begin{array}{c}\text { Economic } \\
\text { potential } \\
\text { mln tn. } \\
\text { f. e. }\end{array}$} & \multicolumn{6}{|c|}{$\begin{array}{c}\text { Prognosis } \\
\text { (economic potential), mln tn. f. e. }\end{array}$} \\
\hline & & & \multicolumn{2}{|c|}{2020} & \multicolumn{2}{|c|}{2025} & \multicolumn{2}{|c|}{2030} \\
\hline & 2016 & & I & II & $\mathbf{I}$ & II & I & II \\
\hline Straw of grain crops & 33,5 & 5,47 & 6,62 & 6,02 & 7,44 & 6,73 & 8,10 & 7,00 \\
\hline Rape straw & 4,0 & 0,91 & 1,10 & 1,00 & 1,24 & 1,12 & 1,35 & 1,16 \\
\hline Waste of corn production & 40,2 & 4,43 & 5,36 & 4,87 & 6,02 & 5,45 & 6,56 & 5,67 \\
\hline Waste of sunflower production & 21,0 & 1,92 & 2,32 & 2,11 & 2,61 & 2,36 & 2,84 & 2,46 \\
\hline Agricultural waste recycling & 6,9 & 1,29 & 1,56 & 1,42 & 1,75 & 1,59 & 1,91 & 1,65 \\
\hline Wood biomass & 16,6 & 4,66 & 5,73 & 5,45 & 6,52 & 5,96 & 7,08 & 6,29 \\
\hline Biodiesel from rape & - & 0,49 & 0,60 & 0,64 & 0,68 & 0,61 & 0,74 & 0,64 \\
\hline $\begin{array}{l}\text { Bioethanol from corn and } \\
\text { sugar beet }\end{array}$ & - & 1,06 & 1,28 & 1,17 & 1,44 & 1,30 & 1,57 & 1,36 \\
\hline $\begin{array}{l}\text { Biogas from waste and by- } \\
\text { products of agro-industrial } \\
\text { complex }\end{array}$ & $\begin{array}{c}1,6 \text { billion } \mathrm{m} 3 \\
\text { methane }(\mathrm{CH} 4)\end{array}$ & 0,97 & 1,17 & 1,07 & 1,32 & 1,19 & 1,44 & 1,24 \\
\hline $\begin{array}{l}\text { Biogas from solid domestic } \\
\text { waste }\end{array}$ & $\begin{array}{l}0,6 \text { billion } \mathrm{m} 3 \\
\text { methane }(\mathrm{CH} 4)\end{array}$ & 0,26 & 0,31 & 0,29 & 0,35 & 0,32 & 0,38 & 0,33 \\
\hline Biogas from sewage & $\begin{array}{c}\text { 1,0 billion } \mathrm{m} 3 \\
\text { methane }(\mathrm{CH} 4)\end{array}$ & 0,27 & 0,32 & 0,24 & 0,34 & 0,30 & 0,37 & 0,32 \\
\hline $\begin{array}{l}\text { Energy crops: willow, poplar, } \\
\text { miscanthus }\end{array}$ & $\begin{array}{l}11,5 \text { billion } \mathrm{m} 3 \\
\text { methane }(\mathrm{CH} 4)\end{array}$ & 6,28 & 7,60 & 6,91 & 8,54 & 7,72 & 9,29 & 8,04 \\
\hline corn & $\begin{array}{l}3,3 \text { billion } \mathrm{m} 3 \\
\text { methane }(\mathrm{CH} 4)\end{array}$ & 3,68 & 4,45 & 4,05 & 5,00 & 4,53 & 5,45 & 4,71 \\
\hline Peat & - & 0,40 & 0,48 & 0,44 & 0,54 & 0,49 & 0,59 & 0,51 \\
\hline Total & - & 32,09 & 38,83 & 35,30 & 43,64 & 39,47 & 47,49 & 41,08 \\
\hline
\end{tabular}

Note: I - optimistic, II - pessimistic scenario. 
rections of the development of the renewable energy sector and the great potential of biomass available for energy production. The main motivation for biomass heat generation facilities is the independence from imported energy sources, which ensures energy independence of the regions of the country as an important component of the politi$\mathrm{cal}$ and economic independence of the state.

Regional bioenergy as a branch of national bioenergy is closely connected with the socio-economic situation of the country. With the development of bioenergy much more jobs are created, than with the use of any other types of renewable and nonrenewable energy, employment is provided especially in rural areas where moost problems of poverty and unemployment exist; bioenergy development can help to slow down the pace of urbanization.

Thus, the socio-economic importance of bioenergy provides economic development of the territory, social welfare of the population and environmental safety.

Economic evaluation of various options of full or partial replacement of natural gas showed that they can be supplied with wood waste, and the cost of reconstruction of the boiler house will be cost effective. Total capacity of imposed objects of bioenergy program can save annually natural energy resources. This approach saves imported fuels due to use of biofuels; increase of efficiency of fuel conversion due to introduction of modern designs of boiler units; attractiveness for investment through a short payback time and high returns.

Socio-economic aspects of bioenergy solve problems of employment of the population. As the experience of Scandinavian countries shows, highly engineered wood fuel production gives 120 jobs per every TW of bioenergy. The growth of workplaces in the bioenergy creates new workplaces in other industries. In addition, the socio-economic importance of bioenergy is disclosed in accordance with the following criteria: diversification of income and providing employment in rural areas; reduction of energy supply costs for agrarian enterprises and energy tariffs for the population; providing autonomy (independence) from centralized power grids; reduction of the ecological load level, energy utilization of waste; effective use of biomass resources.
Particular attention is paid to environmental safety during the sustainable development of biotechnology is directly related to biomass energy production on reducing the greenhouse effect and environmental damage from waste collection systems, providing of an environmentally closed energy system. Bioenergy installations are an effective means of recycling livestock waste, waste in cutting down the forest and timber industry and city garbage dumps.

The ecological situation, which has developed now in Ukraine is crisis and is of great concern of both Ukrainian and international society. Factors that led to the emergence of environmental problems include in particular, neglect of objective laws of development and reproduction of the natural resource complex for a long time, high proportion of resource-intensive and energy-intensive technologies in livestock production, low environmental awareness of society. These factors influence the significant degradation of the environment of Ukraine.

Today, eco-functioning business should be the fullest use of market mechanisms to solve environmental problems of industries and society as a whole. In this way, it is advisable to use the experience of developed countries, which proves at the mandatory state system of technical regulation in the environmental field, the effectiveness of implementing voluntary (stimulating) environmental and economic instruments, as well as green purchases in state and public sectors.

Comparing the economic efficiency of bioenergy and traditional energy, one should focus not only on the basic information on the cost of energy production and capital investment in the construction of relevant facilities, but also taking into account future risks, caused by rising prices for traditional fuels and environmental costs, preservation of public health in terms of increasing pollution, emitted by power plants operating only through the use of coal, fuel oil and natural gas. Taking into account the above mentioned risks, we can conclude that bioenergy technologies in the coming decades will be able to compete with traditional energy technologies in the electricity generation market. 
Active development of bioenergy in different countries of the world, aimed at replacing the traditional hydrocarbon energy and solving the problems of ecological and energy security, allows to distinguish the following promising tasks of this industry in the world economy:

1) further increase capacity for the production of fuel, heat and electricity from biomass and biowaste;

2) development of innovative ecological-oriented bioenergy technologies which increase the energy and economic efficiency of fuel and energy production from biomass, as well as reduces the ecological burden on the environment (these technologies primarily include the production and use of liquid and gaseous biofuels second generation which is obtained by different methods of pyrolysis of biomass. getting third-generation biofuel from algae and genetic modification of biogenic origin of raw materials for energy purposes);

3) improvement of models of state regulation of bioenergy development;

4) development of international cooperation in the field of bioenergy;

5) development and implementation of bioenergy projects at regional and national levels.

\section{DISCUSSION}

It was proven that biofuels will allow fully replace traditional energy, improve the competitiveness of the national economy and reduce the amount of harmful emissions into the environment. The current energy crisis requires immediate actions to solve the socio-economic problem of energy security, which can only be resolved through rational use of all existing on Earth and the environment sources of fuel and energy or search for alternative energy sources. One of the possible ways of bioenergy technologies implementation in Ukraine is only possible by attraction of foreign investors. At the same time, partial state funding is also possible. In this case producer companies receive state support in the form of a site prepared for construction with the necessary infrastructure (communications, access roads). A similar scheme gives certain guarantees to potential investors, facilitates their access to the market (it is not a secret that the procedure for all sorts of approval may require significant financial and time resources). For the creation of bioenergy infrastructure, state must spend a lot of money by providing long-term investments which subsequently ensure the creation of jobs, as well as reduce utility bills and increase tax revenues from the production sphere. In the context of the financial and economic crisis and political instability, the development of the bioenergy industry is a priority in solving the main problems of socio-economic importance.

Scientific and practical developments of many authors mainly focus on implementation of technologies for use of alternative energy sources. However, the problem of finding sources of funding for such projects got not enough attention. Moreover, the issues of determining the criteria for the effectiveness of selection and financing of alternative energy projects will require further research. Exactly the further financial and economic substantiation of scientific and practical implementation of alternative energy sources will allow to identify perspective and high-efficiency projects that will ensure the stability of the country's energy independence.

\section{CONCLUSION}

Ukraine has great potential for the development of renewable energy sources, which is of particular importance in the context of the energy crisis, as well as rising prices for traditional energy sources and a high degree of dependence of the country on energy resources import. One of the ways to solve not only energy problems, but also socio-economic and environmental ones, are switching to alternative forms of clean fuels from renewable energy sources. Therefore, the development of bioenergy in Ukraine should be considered as an important factor of increasing the level of energy security and reducing the negative impact of energy on the environment. 
In terms of financial and economic instability, the development of bioenergy industry is a priority in ensuring the energy independence of the country. Effective bioenergy development in a harsh competitive environment can be ensured through comprehensive support from the state and targeted state funding. Investment-attractive areas for the implementation of bioenergy technologies are public-private partnership and creation of favorable conditions for attraction of direct foreign investments. Today, Ukraine successfully implemented alternative energy projects funded by international funds, consortiums, and Ukrainian banks. Therefore, rational use of funds from financial donors and partners allowed the Ukrainian industry and agriculture to implement bioenergy projects that ensured the efficiency of management.

Thus, the priority direction of bioenergy development is energy supply of consumers by alternative energy sources; resource conservation (natural resources) due to the use of bioenergy resources; region increases self-sufficiency of bioenergy resources in order to reduce dependence on centralized energy grids; reduce air pollution (biofuel called "environmentally friendly energy source") and reduction of area landfills (processing, recycling of waste) due to the processing of biomass.

\section{REFERENCES}

1. Association of Bioenergy Structures. Presentation of the updated Energy Strategy of Ukraine till 2025. Retrieved from http://abc. in.ua/07-chervnya-2017-rokuvidbulas-prezentaciya-o/

2. Danchuk, I. (2015). Documentation of Best Practices in the Use of Bioenergy Technologies in the Municipal Sector in Ukraine. Retrieved from http://bioenergy.in.ua/media/ filer_public/2a/3d/2a3da4995057-4a5f-8e5b-565a52daf34c/ dokumentuvannia_naikrashchikh_ praktik_zast_bioenerget_tekhnologii.pdf

3. Smeets, E. (2008). General base line and principles. Report on WP4.1 of the EC FP7 Project "Biomass Energy Europe". Copernicus Institute, Utrecht University, the Netherlands. Retrieved from http:// www.eu-bee.com

4. Geletuha, G., \& Zhelyezna, T. (2015). Development of bioenergy as a tool for replacing natural gas in Ukraine. Bioenerhetyka, 1, 1-20.

5. Geletukha, G., Zhelezna, T., Zhovmir, M. et al. (2010). Assessment of energy potential of biomass in Ukraine. Part 1.
Agricultural waste and wood mass. Industrial heat engineering, 32(6), 58-65.

6. Kaletnik, H. (2008). Development of biofuel market in Ukraine (p. 464). Sumy: Agricultural science.

7. Khivrych, O. (2011) Energy plants as raw materials for biofuels. Proposition, 6, 68-73.

8. Makarchuk, O. (2011). Bioenergy potential of agricultural production: economic dimension, use forecast (177 p.). Kyiv. Agrar Media Group.

9. Martijn, V. (2010). Harmonization of biomass resource assessments. Volume I: Best practices and methods handbook. Report on WP5 of the EC FP7 Project "Biomass Energy Europe" BTG Biomass Technology Group B.V., the Netherlands. Retrieved from http://www.eu-bee.com

10. Matveeva, Y. (2008). Biomass: modern prospects for the most ancient fuels. Zelena enerhetyka, 2(30), 22-28.

11. Messel-Veselyak, V., Pastetsky, V. (2011). Efficiency of alternative types of energy in agriculture of Ukraine. Ekonomika APK, 12, 3-9.
12. Mykytenko, V. (2006). Energy efficiency of national economy: social-economic aspects. Bulletin of the National Academy of Sciences of Ukraine, 10, 17-26.

13. Myronenko, M., Polova, O. (2016). Social-economic meaning of bioenergy and perspectives of innovation breakthrough. Investments: practice and experience, 7, 24-29.

14. Polova, O. (2010). Bioenergy assessment of the use of animal wastes (248 p.). Zhytomyr. Ruta.

15. Solovey, O., \& Lega, Y. (2007). Alternative and renewable energy sources (p. 481). Sumy: CHDTU.

16. The World Bank (2017). OECDFAO Agricultural Outlook 2011-2020. Retrieved from http:// stats.oecd.org/OECDStat_Metadata /Show Metadata.ashx? Dataset=HIGH_AGLINK_2011 \&Show OnWeb=true\&Lang=en

17. World trends in the energy sector. Retrieved from http://rener.com. ua/news/77

18. Yermilov, S. (2006) Problems and ways to improve the state policy of Ukraine in the field of energy saving. Economy Ukraine, 9, 4-11. 